\title{
Evaluation of Groundwater Potentials for Borehole Drilling by Integrated Geophysical Mapping of Auchi-South Western Nigeria Using Very Low Frequency Electromagnetic Profiling (VLF-EM) and Vertical Electrical Sounding (VES)
}

\section{CHINYEM, FI}

\author{
Department of Geology, Delta State University, P.M.B. 1, Abraka, Nigeria \\ E-mail: fichinyem@gmail.com
}

\begin{abstract}
An integrated geophysical survey involving Very Low Frequency Electromagnetic (VLF-EM) and electrical resistivity sounding was conducted at AuchiSouthwestern Nigeria, in order to delineate the fissured zones and associated groundwaterbearing media for borehole drilling in the study area. The area is underlain by the Precambrian Basement Complex rocks and in some places sedimentary rocks. The VLF-EM traverses were established along two traverses using ABEM-WADI equipment, with a station interval of $10 \mathrm{~m}$ and with lengths ranging from 200 to $240 \mathrm{~m}$. Linear fissures presumed to be geologic fissures inferred from the filtered real and filtered imaginary assisted in selecting seven VES points that were further probed using ABEM SAS 1000 Resistivity meter. The spreading were conducted using the convectional Schlumberger electrode configuration with half-current electrode separation $(\mathrm{AB} / 2)$ that ranged from 1 to $225 \mathrm{~m}$,was used for the sounding. The VES data were presented as depth sounding curves and were suitably iterated using Schlumberger O'Neil software. The VLF filtered real profile showed a high peak trend signifying a fracture signature. The delineated weathered and basement column constituted the aquifer units for borehole drilling. Six lithologic formations were delineated which included the top soil, clay/shale, fine grained sand, coarse grained sand, fractured bedrock and fresh bedrock. Four Model field curves were delineated which included HAKQ, HKQQ, KHAA and KHKH. There are two main targets for groundwater exploration in the study area. These included the weathered zone (fine and medium grained sand) and the fractured zone. The thickness of these zones varied between 15.2 to $50.1 \mathrm{~m}$. Based on the geophysical parameters such as thin overburden thickness, clayey weathered layer and low fractured basement characterized by the study area, it is therefore inferred that the groundwater potential of the area is low. Nevertheless, the study has justified the use of integrated geophysical mapping as a better tool in evaluating the groundwater potential in crystalline terrains. $\odot$ JASEM

https://dx.doi.org/10.4314/jasem.v21i4.9
\end{abstract}

Keywords: Integrated geophysical survey, electromagnetic profiling, vertical electrical sounding, groundwater resources, Auchi

Groundwater consists of all subsurface water trapped in the pores and other open spaces in rocks, sediment and soil (Monroe and Wicander, 2005). It is a significant part of the hydrologic cycle containing about $21 \%$ of the world's supply of freshwater (Adepelumi et al., 2013). Groundwater occurs in a highly permeable and porous geological formation known as aquifers which have the properties that allow storage and movement off water (Eduvie, 2006; Taiwo et al., 2016).Groundwater can be abstracted by drilling boreholes and hand-dug wells within the permeable geological formation. Nevertheless, the study area is underlain by Precambrian Basement Complex rocks where groundwater is usually contained in the weathered and/or fractured basement rocks (Jayeoba and Oladunjoye, 2013). The highest groundwater yield in basement terrain is found in areas where thick overburden overlies fractured zones (Olorunniwo and Olurunfemi, 1987; Taiwo et al., 2016). These zones are often characterized by relatively low resistivity. But, the indiscriminate drilling of boreholes without employing pragmatic and scientific approach, that is pre-drilling geophysical investigation, has led to the unsuccessful boreholes with low yield (Bayode et al; 2007). It is against this background that the evaluation of groundwater potential in the area was carried out.

Thus, geophysical methods especially electromagnetic and resistivity methods are commonly used in groundwater exploration, mainly due to the close relationship between electrical and some hydrological parameters. The Very Low Frequency Electromagnetic (VLF-EM) is an effective tool in mapping conductive fault and fracture zones, while resistivity method is used for detecting groundwater presence and differentiating sub surface layers. Electromagnetic and electrical methods have been widely used in groundwater investigations because of good correlation between electrical properties, geological (composition) and fluid content (Olayinka et al; 2004, Khali, 2009; Jayeoba and Oladunjoye, 2013; Chinyem et al; 2014; Taiwo et al; 2016). In this present study, Very Low 
FrequencyElectromagnetic (VLF-EM) and Vertical Electrical Sounding (VES) methods were employed with the aim of evaluating the groundwater potentials of Auchi area for borehole drilling.

\section{MATERIALS AND METHODS}

Description of study area with maps and Locations:The study area lies within latitude $7^{0} 3^{1} 00^{11}$ to $7^{0} 4^{1} 30^{11} \mathrm{~N}$ and longitude $6^{0} 15^{1} 0^{11}$ to $6^{0} 18^{1} 0^{11} \mathrm{E}$ (Figure 1). The climate is classified as a tropical savanna with a tropical dry forest biozone. The area has an annual rainfall of about $1,300 \mathrm{~mm}$ and annual temperature range of between $18^{0}$ to $33{ }^{0} \mathrm{C}$. The landscape is mostly covered with mosaic forest shrub land and grass land. The study area falls within the localities where the lithofacies of the Niger Delta grade gradually into that of the Anambra Basin. The geologic setting of the area is typical of the intrusive granites and migmatite gneiss complex of Southwestern Nigeria (Rahaman, 1976). The area is underlain by a sequence of sedimentary formations which consists of laterite, clay/shale, clayey sand, fine and coarse sandstones and the basement complex rocks.

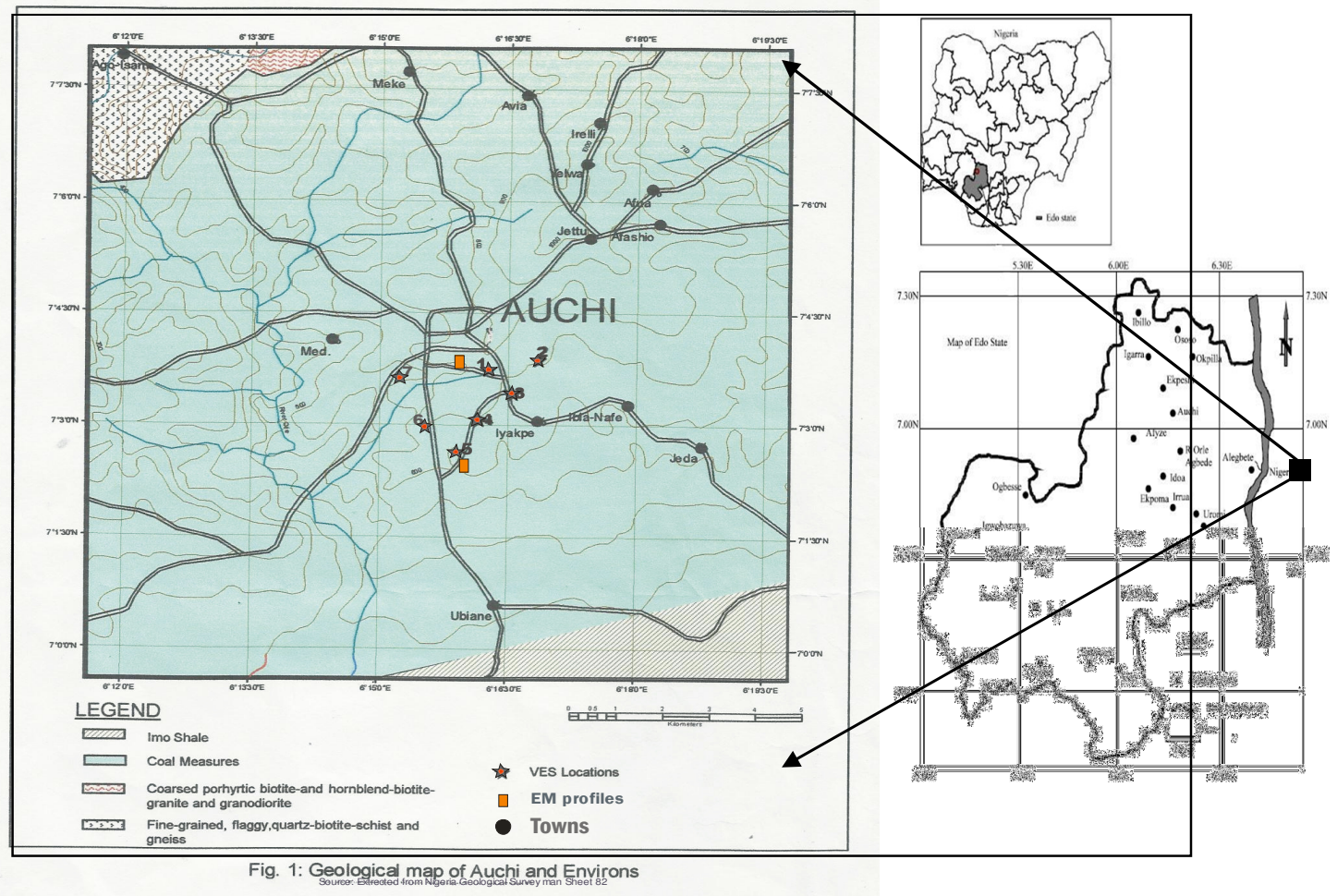

Fig 1: Location map of the study area showing EM profiles and VES locations.

DataSampling: The integrated geophysical field investigation involved application of both Very Low Frequency Electromagnetic (VLF-EM) measurement and Vertical Electrical Sounding (VES) for mapping fractures in the bedrock and delineating geoelectric layers in the overburden materials. The VLF-EM data were acquired with the aid of ABEM WADI equipment. Two profiles were measured with each profile trending approximately N-S and E-W directions respectively to effectively monitor the subsurface inhomogeneity. The VLF-EM data were sampled at $10 \mathrm{~m}$ intervals along two profiles ranging 200to $240 \mathrm{~m}$. A Global Positioning System (GPS) was used for exact spatial positioning of the sampled data. Seven Vertical Electrical Sounding (VES) data were subsequently acquired at the locations of the anomaly identified in the VLF-EM profiles (Figures 2 and 3) with the aid of ABEM signal Averaging System (SAS) 1000 Tetrameter Resistivity Meter. The VES utilized the Schlumberger electrode array with half - current electrode Separation $(\mathrm{AB} / 2)$ ranging from 1 to $225 \mathrm{~m}$. The co-ordinates of each VES station were taken with the GPS device to ensure accurate future geo-referencing. 


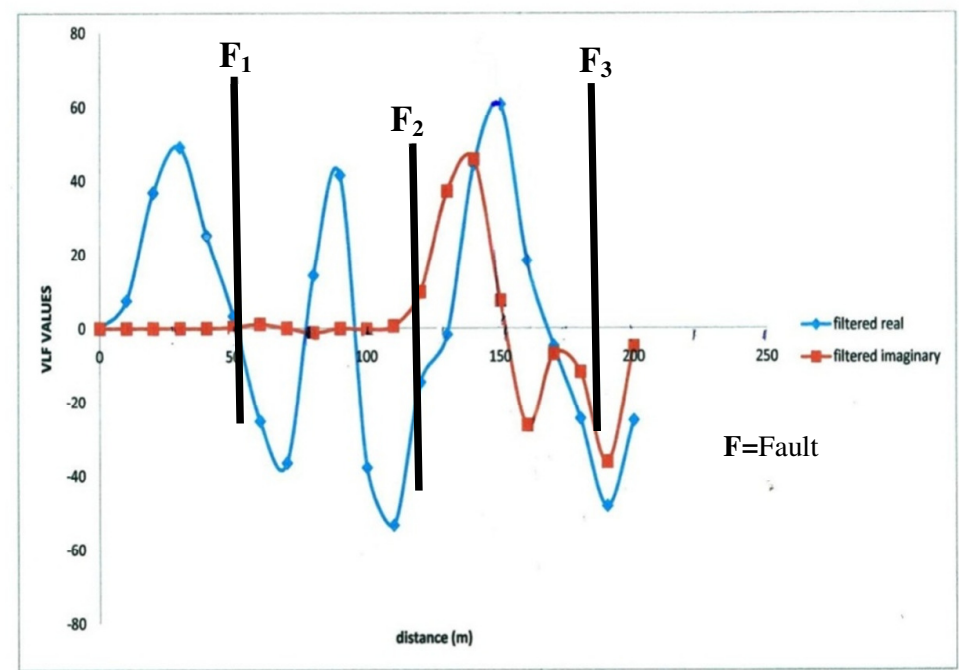

Fig 2: VLF-EM Profile along Traverse 1

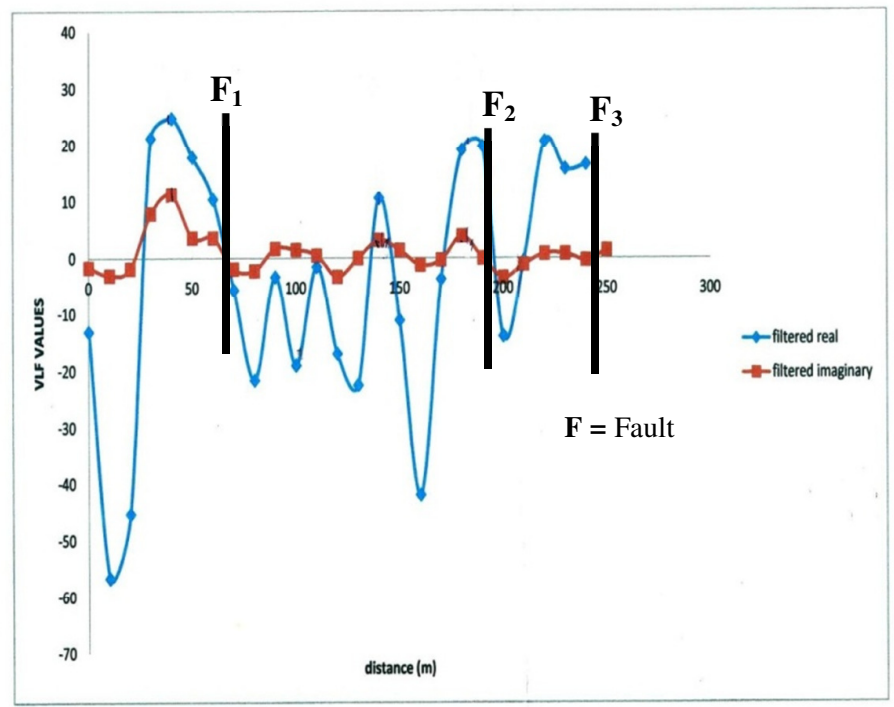

Fig 3: VLF-EM Profile along Traverse 3

Data Processing and Data Interpretation: The VLFEM data in addition to the VES measurements were subjected to data processing as the basis for interpretation. For VLF-EM, the acquired field data were processed to simplify the obtained complex information into a profile in which the displayed function is directly related to physical properly of the underlying rock. Hence, measured raw real and imaginary components were subjected to Fraser (Fraser, 1969) and Karous-Hjeit (Karous and Hjeilt, 1983) filtering operations in order to suppress noise and enhance the signal. The raw real (in phase) and the raw imaginary (quadrature) components acquired in the field were subjected to filtering process to generate the filter real and the filter imaginary part data. The raw real as well as the raw imaginary data were converted with the aid of an in-built filtering program provided in the ABEM WADI equipment. Freely available MATLAB-based software (Sundarajan et al; 2011) was used to process the measured components of the VLF-EM data. The filtered real data anomaly inflections appear as peak positive anomalies and false VLF anomaly inflections as negative anomalies of the profiles (Adiat et al; 2009). Subsequently the filtered real in addition to the filtered imaginary data was plotted against distance to generate the VLF-EM profiles. Thus, this formed the basis for the overall interpretation and delineation of potential fracture zones.

The VES data presented as depth sounding curves (Figures 4 and 5) were inverted with the aid of computer aided iteration curve matching techniques. The apparent resistivity obtained was plotted on a 
log-log graph paper with the electrode separation $(\mathrm{AB} / 2)$ on the abscissa and apparent resistivity $\left(\rho_{\mathrm{a}}\right)$ values as the ordinate. The true resistivity and thickness of the subsurface layers were interpreted by partial curve matching with the two layer model master curves and the corresponding auxiliary curves. The thickness and resistivity values obtained from the partial curve matching were then used for a quantitative computer iteration using the

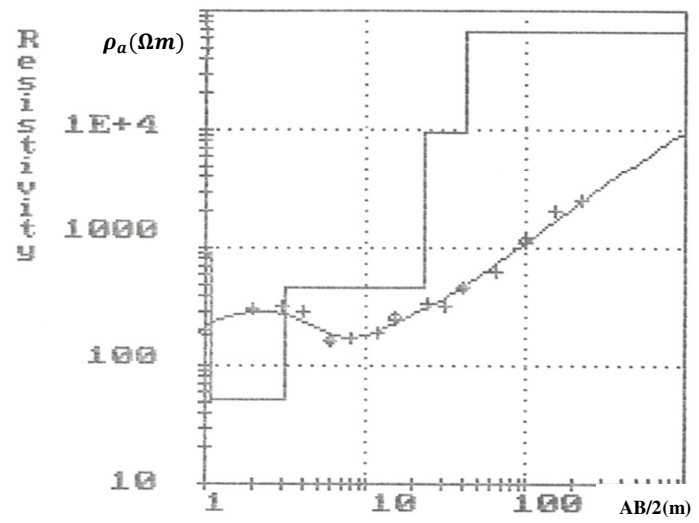

Fig 4: Typical VES curve for Auchi (VES 4)
Schlumberger O'Neil software package (Schlumberger, 1986). The results obtained from the computer modeling are presented in Table 1. The iterated geoelectric parameters (Table 1) were used to generate geo-electric sections for the study area (Figures 6 and 7) in accordance with the analysis of the geo-electrical data

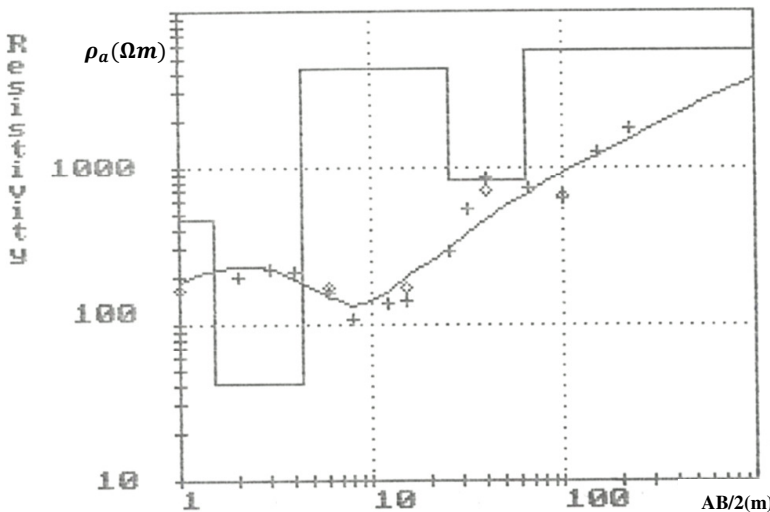

Fig 5: Typical VES curve for Auchi (VES 5)

Table 1: Geoelectric layers' parameters deduced from computer iterationand modeling of the VES curves from Auchi area

\begin{tabular}{|c|c|c|c|c|c|c|}
\hline VES Location & Layer & $\begin{array}{l}\text { Resistivity } \\
\text { (Ohm-m) }\end{array}$ & $\begin{array}{l}\text { Thickness } \\
\text { (m) }\end{array}$ & $\begin{array}{l}\text { Depth } \\
\text { (m) }\end{array}$ & Inferred Lithology & Model Curve \\
\hline VES 1 & $\begin{array}{l}1 \\
2 \\
3 \\
4 \\
5 \\
6\end{array}$ & $\begin{array}{l}297 \\
101 \\
960 \\
1080 \\
370 \\
299\end{array}$ & $\begin{array}{l}0.6 \\
0.8 \\
7.2 \\
32.7 \\
49.7 \\
-\end{array}$ & $\begin{array}{l}0.6 \\
1.4 \\
8.6 \\
41.3 \\
91.0 \\
-\end{array}$ & $\begin{array}{l}\text { Top soil } \\
\text { Clay/shale } \\
\text { Medium grained sand Medium grain sand Fine } \\
\text { grained sand } \\
\text { Fine grained sand }\end{array}$ & HAKQ \\
\hline VES 3 & $\begin{array}{l}1 \\
2 \\
3 \\
4 \\
5 \\
6\end{array}$ & $\begin{array}{l}165 \\
1190 \\
69.1 \\
529 \\
11400 \\
56800\end{array}$ & $\begin{array}{l}0.3 \\
0.6 \\
2.0 \\
15.2 \\
16.2 \\
-\end{array}$ & $\begin{array}{l}0.3 \\
0.9 \\
2.9 \\
18.1 \\
34.3 \\
-\end{array}$ & $\begin{array}{l}\text { Top soil } \\
\text { Medium grained sand Clay/shale } \\
\text { Fine grained sand } \\
\text { Fractured bedrock } \\
\text { Fresh bedrock }\end{array}$ & KHAA \\
\hline VES 5 & $\begin{array}{l}1 \\
2 \\
3 \\
4 \\
5 \\
6\end{array}$ & $\begin{array}{l}116 \\
472 \\
41 \\
4380 \\
810 \\
5530\end{array}$ & \begin{tabular}{l|l|}
0.4 \\
1.1 \\
2.8 \\
20.7 \\
37.9 \\
-
\end{tabular} & \begin{tabular}{l|l|}
0.4 \\
1.5 \\
4.3 \\
25.0 \\
62.7 \\
- \\
\end{tabular} & $\begin{array}{l}\text { Top soil } \\
\text { Fine grained sand } \\
\text { Clay/shale } \\
\text { Fractured bedrock } \\
\text { Medium grained sand } \\
\text { Fracture bedrock }\end{array}$ & KHKH \\
\hline VES 6 & $\begin{array}{l}1 \\
2 \\
3 \\
4 \\
5 \\
6\end{array}$ & $\begin{array}{l}158 \\
726 \\
94 \\
527 \\
14400 \\
60500\end{array}$ & \begin{tabular}{l|l|}
0.4 \\
0.9 \\
2.2 \\
19.2 \\
21.5 \\
-
\end{tabular} & \begin{tabular}{l|l|}
0.4 \\
1.3 \\
3.5 \\
22.7 \\
44.2 \\
-
\end{tabular} & $\begin{array}{l}\text { Top soil } \\
\text { Fine grained sand } \\
\text { Clay/shale } \\
\text { Fine grained sand } \\
\text { Fractured bedrock } \\
\text { Fresh bedrock }\end{array}$ & KHAA \\
\hline
\end{tabular}




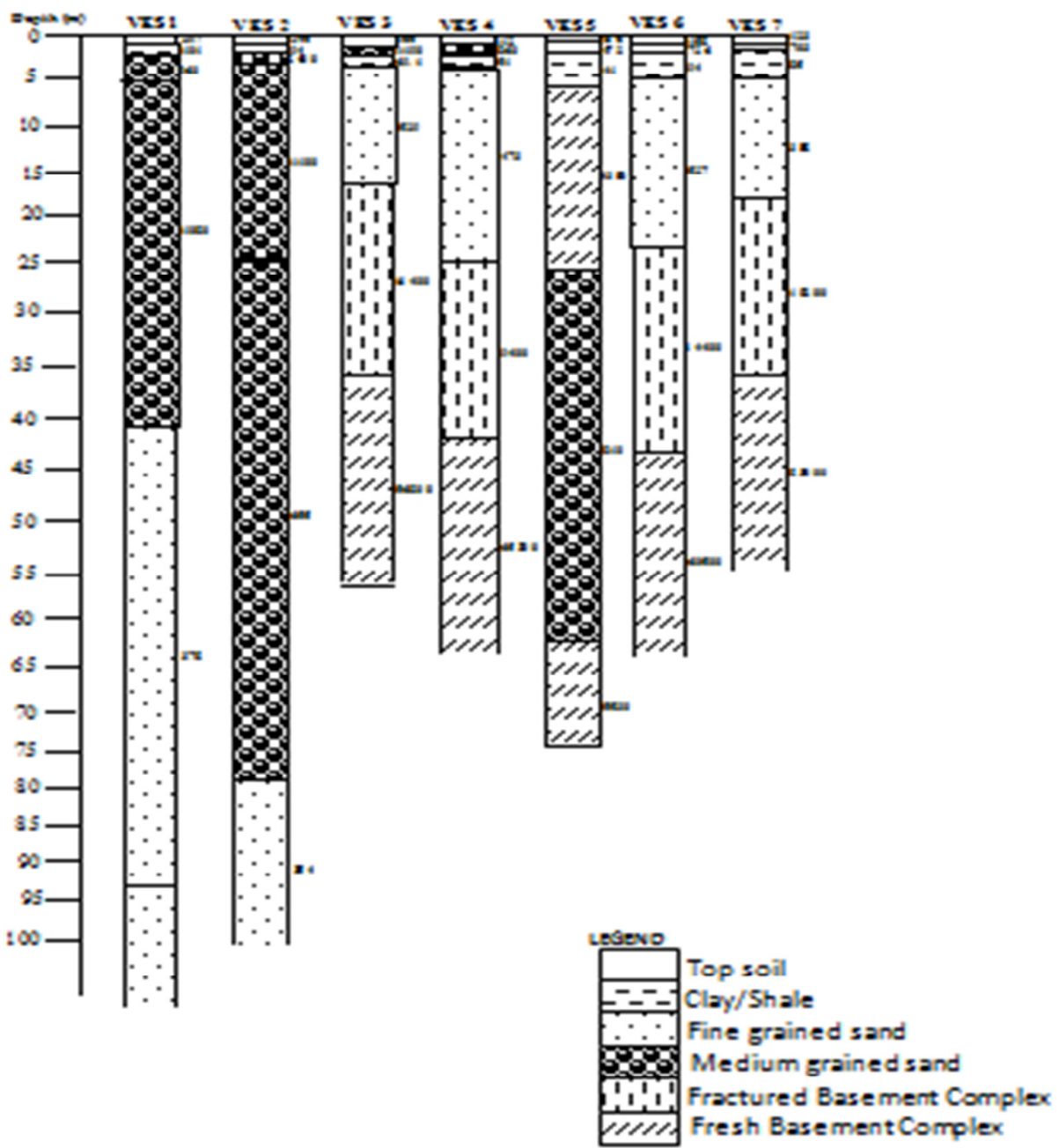

Fig 6: Geolectric section of VES 1 - 7 showing lithologic distribution. 

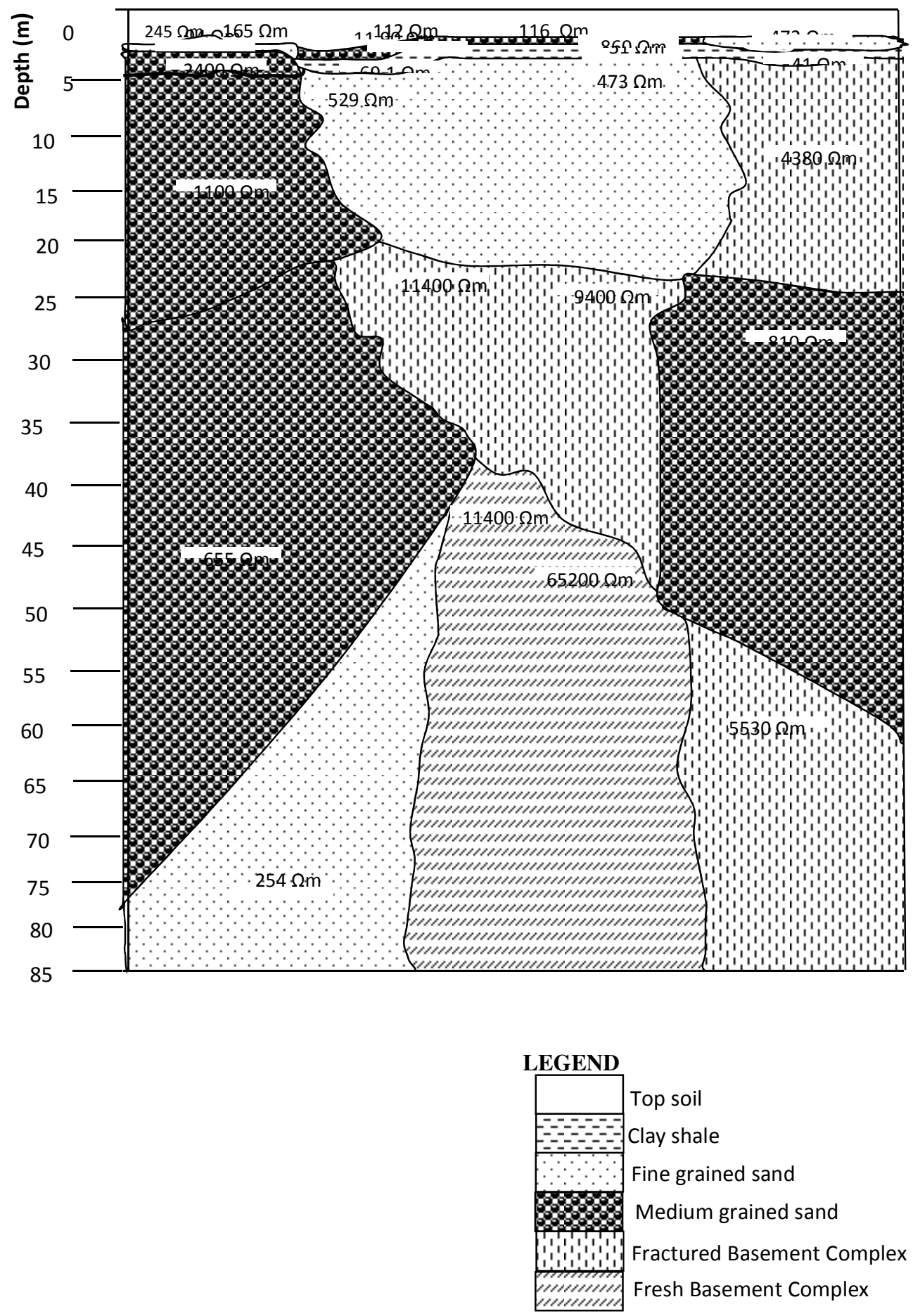

Fig 7:Geoelectric Section of the study area showing near surface lithologic distribution across VES 2, 3, 4 and 5. 


\section{RESULTS AND DISCUSSION}

The results, which evolved from the VLF-EM and VES data interpretation are presented as profile and geoelectric sections. The results are aimed at explaining the subsurface conducting and or resistivity in the study area. Conductive features, which are characterized by significant positive filtered VLF-EM peaks (Figures 2 and 3), were interpreted as probable geologic fissures capable of holding appreciable quantity of water. The VLE-EM anomalies varied greatly. The values of the filtered real ranged from -42.0 to 65.6 while those of the filtered imaginary ranged from -3.4 to 11.2 across the study area. The profiles of the VLF-EM sections (Figures 2 and 3) contained significant maxima in the filtered real part and only a small anomaly is the imaginary part. Zones with peak positive filtered real anomalies were considered areas for electrical soundings since they often correspond to zones of high conductivity. Figure 2 shows the VLF-EM profile along traverse1. Several positive peaks were delineated as fractures $\left(\mathrm{F}_{1}, \mathrm{~F}_{2}\right.$ and $\left.\mathrm{F}_{3}\right)$ at distances between 10 and $40 \mathrm{~m} ; 80$ and $90 \mathrm{~m}$; and $140 \mathrm{~m}$ respectively on the filtered real as shown in Figure 2. Figure 3 also shows VLF-EM profile along traverse 2. Different features of varying degree of conductivity (fractures) were delineated. For example, between stations 10 and 30m; 140 and 150 $\mathrm{m}$; and $170 \mathrm{~m}$ and $200 \mathrm{~m}$ respectively, the in-phase profiles show positive peaks of varying intensities and sharpness, suggesting the presence of a shallow and deep conductors. These points are zones of interest in groundwater abstraction in hard rock terrains.

The VES data obtained were interpreted by partial curve matching and computer iteration techniques. From the interpretation, the geoelectric parameters of the subsurface layers were deduced as presented in Table 1. The resistivity sounding curves obtained from the study area consist of 6-layers (HAKQ, KKQQ, KHKH and KHAA with the KHAA type being the predominant). The typical VES curve types are shown in figures 4 and 5 and they correspond to the VES data from the study area. Figure 4 is characteristic of typical KHAA model curve and it consists of top soil, medium sand, clay/shale, fine sand, fractured bedrock while figure 5 represents KHKH curve type and it consists of top soil, fine sand, clay/shale, medium sand and fractured bedrock. Figures 6 and 7 show the geoelectric cross sections generated from VES interpretation results. The sections show the subsurface variation in electrical resistivity along the profiles and an attempt to correlate the geoelectric sequence across the profiles (Figure 7).

The two dimensional view of the geoelectric parameters (resistivity and depth) obtained from the inversion of the electrical resistivity sounding data are represented as geoelectric sections. The geoelectric section obtained from the sounding curves revealed a six layer earth model of the subsurface categorized into the top soil, clay / shale, fine grained sand, coarse grained sand, fractured and fresh basement. The top soil which is relatively thin has resistivity values between 112 to $245 \Omega \mathrm{m}$ and thickness values between 0.3 to $0.8 \mathrm{~m}$, characteristic of lateritic soil. Beneath the top soil layer is a layer characterized by medium grained sand at VES 1 and VES 4 which terminates at VES 5 and this composed of fine grained sand. VES 2 is composed of clay and this does not extend to VES 3. This layer is characterized by resistivity values that ranged from 94 to $1190 \Omega \mathrm{m}$ with thickness which ranged from 0.6 to $1.1 \mathrm{~m}$ at a depth which varied from 0.9 to $1.6 \mathrm{~m}$. The third layer has resistivity values that ranged from 41 to $2400 \Omega \mathrm{m}$. This clearly depicts a clayey layer at VES 3, 4 and 5 except at VES 2 where it is medium grained sand. It has a varying thickness of 2.0 to $2.8 \mathrm{~m}$ and a depth range of 2.9 to $4.3 \mathrm{~m}$. The aquiferous units are located in layers 4,5 and 6 of VES 2 and VES 5; and layers 4 and 5 of VES 3 and VES 4 . These aquiferous units are characterized by resistivity values ranging from 473 to $11400 \Omega \mathrm{m}$ with thickness values ranged between 15.2 and $50.1 \mathrm{~m}$ and at depths between 18.1 and $76.8 \mathrm{~m}$. These aquiferous layers are presumed to have resulted from highly fractured and weathered bedrock. The bedrock is observed to be fractured which appears as vertical conductors on the VLF - EM profiles at VES 5. This indicates that the location (VES 5) is most suitable for sitting most borehole in the area. The fresh bedrock is characterized by resistivity values that ranged from 56800 to $83000 \Omega \mathrm{m}$. In general, the study revealed the groundwater potential of the area to be generally low with limited hydrogeological importance.

Conclusion: The integrated geophysical methods used in this study have immensely assisted in evaluating groundwater potential of AuchiSouthwestern Nigeria, as it has enhanced the knowledge of the hydrogeology of area and this will assist groundwater development and management activities. Furthermore, the study has provided knowledge on the capabilities of integrated geophysical methods in delineating areas of groundwater occurrence in the area. Hence, an integrated geophysical mapping is highly recommended before borehole drilling in areas with similar geologic framework across Nigeria so as to avoid loses caused by drilling abortive or unproductive boreholes.

\section{REFERENCES}

Adepelumi, AA; Akinmade, OB; Fayemi, O (2013). Evaluation of Groundwater Potential of Baikin, Ondo State Nigeria using Resistivity and 
Magnetic Techniques: Universal Journal of Geosciences 1 (2); 37-45.

Adiat, KAN; Olayanju, GM; Omosuyi, GO; Ako, BD (2009).Electromagnetic profiling and Electrical Resistivity Sounding in Groundwater Investigation of a Typical Basement Complex.A case study of Oda Town, Southwestern Nigeria. Ozean Journal of Social Sciences 21(4): 333-359

Bayode, S; Ojo, JS; Olorunfemi, MO (2007).Geophysical Exploration for Groundwater in Ejigbo and its Environs, Southwestern Nigeria .Global Journal of Geological Sciences 5(1):41 49

Eduvie, MO (2006). Borehole Failures and Groundwater Development in Nigeria. A paper presented at National Seminal Held on the Occasion of Water Africa Exhibition, Lagos, Nigeria on $5^{\text {th }}$ November 2006.

Fraser, DC (1969).Contouring VLF-EM Data Geophysics 34:958-967.

Jayeoba, A; Oladunjoye, MA (2013). Hydrogeophysical Evaluation of Groundwater Potential in Hard Rock Terrain of Southwestern Nigeria. RMZ-M \& G. 60: $271-285$

Karous, M; Hjelt, S E (1983). Linear Filtering of VLF Dip-Angle measurements. Geophysical Prospecting 31:782-894

Khali, MH, (2009). Hydro-geophysical Assessment of Wdi El-Sheikh aquifer, Saint Katherine South
Sinia Egypt. Journal of Environmental and Engineering Geophysics 14 (2):77-86.

Monroe, JS; Wicander, R (2005).Physical Geology ( $5^{\text {th }}$ Edition).Thomson Learning Inc; USA, 644.

Olayinka, AI; Amidu, SA; Oladunjoye, MA (2004).Use of Electromagnetic Profiling and Resistivity Sounding for Groundwater in the Crystalline Basement Area of Igbeti, Southwestern Nigeria.Global Journal of Geological Sciences.2(2): 243 - 253

Olorunniwo, MA; Olorunfemi, $\quad$ MO (1987).Geophysical Investigation for Groundwater in Precambrian Terrains; A case History from Ikare, Southwestern Nigeria. Journal of African Earth Science 6(6): 787- 796

Sundararajan,N; Gnaneshwar, P; Shivaji,A, Srinivas, Y (2011).Very Low Frequency (VLFEM) Measurements in the SchirmacheroasenArea,East Antarctica. Polar Science 5 (1):11-19.

Taiwo, SM; Awoyemi, AO; Onyedim, GC (2016).Combined Use of Very Low Frequency Electromagnetic (VLF-EM) and Electrical Resistivity Survey for Evaluation of Groundwater Potential of Modomo/Eleweran Area, Southwestern Nigeria. African Journal of Environmental Science and Technology. 10(7): $192-206$ 